\title{
Global Burden Related to Nitrous Oxide Exposure in Medical and Recreational Settings: A Systematic Review and Individual Patient Data Meta-Analysis
}

\author{
Abderrahim Oussalah ${ }^{1,2,3}$, Mélissa Julien ${ }^{2}$, Julien Levy ${ }^{2}$, Olivia Hajjar ${ }^{2}$, Claire Franczak ${ }^{2}$, \\ Charlotte Stephan ${ }^{2}$, Elodie Laugel ${ }^{2}$, Marion Wandzel ${ }^{2}$, Pierre Filhine-Tresarrieu ${ }^{2}$, \\ Ralph Green ${ }^{4}$ and Jean-Louis Guéant $1,2,3, *$ (D) \\ 1 University of Lorraine, INSERM UMR_S 1256, Nutrition, Genetics, and Environmental Risk \\ Exposure (NGERE), Faculty of Medicine of Nancy, F-54000 Nancy, France; \\ abderrahim.oussalah@univ-lorraine.fr \\ 2 Department of Molecular Medicine and Personalized Therapeutics, Division of Biochemistry, \\ Molecular Biology, Nutrition, and Metabolism, University Hospital of Nancy, F-54000 Nancy, France; \\ m.julien2@chru-nancy.fr (M.J.); j.levy@chru-nancy.fr (J.L.); o.hajjar@chru-nancy.fr (O.H.); \\ claire.franczak@gmail.com (C.F.); charlotteanne.stephan@gmail.com (C.S.); e.laugel@chru-nancy.fr (E.L.); \\ m.wandzel@chru-nancy.fr (M.W.); pierre.filhine-tresarrieu@hotmail.fr (P.F.-T.) \\ 3 Reference Centre for Inborn Errors of Metabolism (ORPHA67872), University Hospital of Nancy, \\ F-54000 Nancy, France \\ 4 Department of Pathology and Laboratory Medicine, University of California, Davis, Sacramento, \\ CA 95817, USA; rgreen@ucdavis.edu \\ * Correspondence: jean-louis.gueant@univ-lorraine.fr; Tel.: +33-372746135
}

Received: 23 March 2019; Accepted: 16 April 2019; Published: 23 April 2019

\begin{abstract}
The risk of adverse effects of nitrous oxide $\left(\mathrm{N}_{2} \mathrm{O}\right)$ exposure is insufficiently recognized despite its widespread use. These effects are mainly reported through case reports. We conducted an individual patient data meta-analysis to assess the prevalence of clinical, laboratory, and magnetic resonance findings in association with $\mathrm{N}_{2} \mathrm{O}$ exposure in medical and recreational settings. We calculated the pooled estimates for the studied outcomes and assessed the potential bias related to population stratification using principal component analysis. Eighty-five publications met the inclusion criteria and reported on 100 patients with a median age of 27 years and $57 \%$ of recreational users. The most frequent outcomes were subacute combined degeneration $(28 \%)$, myelopathy $(26 \%)$, and generalized demyelinating polyneuropathy (23\%). A T2 signal hyperintensity in the spinal cord was reported in $68 \%(57.2-78.8 \%)$ of patients. The most frequent clinical manifestations included paresthesia (80\%; 72.0-88.0\%), unsteady gait (58\%; $48.2-67.8 \%)$, and weakness $(43 \% ; 33.1-52.9 \%)$. At least one hematological abnormality was retrieved in $71.7 \%(59.9-83.4 \%)$ of patients. Most patients had vitamin B12 deficiency: vitamin B12 <150 pmol/L (70.7\%; 60.7-80.8\%), homocysteine $>15 \mu \mathrm{mol} / \mathrm{L}$ (90.3\%; 79.3-100\%), and methylmalonic acid $>0.4 \mu \mathrm{mol} / \mathrm{L}$ (93.8\%; $80.4-100 \%)$. Consistently, $85 \%$ of patients exhibited a possibly or probably deficient vitamin B12 status according to the $\mathrm{cB} 12$ scoring system. $\mathrm{N}_{2} \mathrm{O}$ can produce severe outcomes, with neurological or hematological disorders in almost all published cases. More than half of them are reported in the setting of recreational use. The $\mathrm{N}_{2} \mathrm{O}$-related burden is dominated by vitamin $\mathrm{B} 12$ deficiency. This highlights the need to evaluate whether correcting B12 deficiency would prevent $\mathrm{N}_{2} \mathrm{O}$-related toxicity, particularly in countries with a high prevalence of B12 deficiency.
\end{abstract}

Keywords: global health; global burden related to nitrous oxide exposure; medical and recreational settings; individual patient data meta-analysis; nitrous oxide-related toxicity; vitamin B12 deficiency; one-carbon metabolism; homocysteine; methylmalonic acid 


\section{Introduction}

Nitrous oxide $\left(\mathrm{N}_{2} \mathrm{O}\right)$ is a colorless, sweet-smelling gas that has been widely used in dental, emergency, and anesthetic practices. The first use of $\mathrm{N}_{2} \mathrm{O}$ as an anesthetic agent was reported on December 1844 by Dr. Horace Wells, an American dentist who demonstrated insensitivity to pain from a dental extraction after $\mathrm{N}_{2} \mathrm{O}$ inhalation [1]. Before proposing the use of $\mathrm{N}_{2} \mathrm{O}$ as an anesthetic agent, Dr. Wells had attended a demonstration by Gardner Quincy Colton regarding the use of $\mathrm{N}_{2} \mathrm{O}$ as an exhilarating or laughing gas [2]. Joseph Priestley, a British scientist, reported the discovery of $\mathrm{N}_{2} \mathrm{O}$ in 1772 , and since that time the inhalation of this gas as part of the public entertainment had become commonplace [3]. Owing to its physical and chemical properties $\mathrm{N}_{2} \mathrm{O}$ is also used in the food industry as a mixing, foaming, and propellant for the preparation of whipping cream.

It is well known that exposure to $\mathrm{N}_{2} \mathrm{O}$ is associated with a risk of developing neurological and hematological complications [4]. In 1956, Lassen et al. reported the first description of severe bone-marrow depression after prolonged $\mathrm{N}_{2} \mathrm{O}$ anesthesia for treating patients with tetanus $[4,5]$. In one patient from this series, the bone-marrow biopsy on the fifth day of $\mathrm{N}_{2} \mathrm{O}$ anesthesia revealed "strikingly megaloblastic" erythropoiesis and changes in granulocytopoiesis that were typical of "pernicious anemia" [5]. Since this first description of a potential link between $\mathrm{N}_{2} \mathrm{O}$ exposure and myelosuppression, the hypothesis of a disorder related to vitamin B12 metabolism was suggested [6]. The effects of $\mathrm{N}_{2} \mathrm{O}$ exposure are mainly reported through case reports. However, the global burden related to $\mathrm{N}_{2} \mathrm{O}$ exposure, notably regarding its effects on one-carbon metabolism, has never been subject to meta-analysis. Thus, we conducted individual patient data meta-analysis to assess the prevalence of clinical, laboratory, and magnetic resonance findings in association with $\mathrm{N}_{2} \mathrm{O}$ exposure in medical and recreational settings.

\section{Matherials and Methods}

\subsection{Data Sources and Searches}

The literature search was conducted using MEDLINE ${ }^{\circledR}$-indexed literature using the PubMed search engine from the National Centre for Biotechnology Information (www.pubmed.gov) (January 1966 to August 2018) using the following full electronic search strategy: ((protoxide[All Fields] AND ("nitrogen"[MeSH Terms] OR "nitrogen"[All Fields])) OR "Nitrous oxide"[All Fields] OR "nitrogen protoxide"[All Fields] OR "laughing gas"[All Fields] OR whippet[All Fields] OR whippets[All Fields]) AND (b12[All Fields] OR "vitamin b12"[All Fields] OR ("vitamin B12"[MeSH Terms] OR “vitamin B12"[All Fields] OR “cobalamin"[All Fields]) OR ("homocysteine"[MeSH Terms] OR "homocysteine"[All Fields]) OR "methylmalonic acid"[All Fields] OR ("methionine"[MeSH Terms] OR "methionine"[All Fields]) OR "folic Acid"[All Fields]). Additional articles were retrieved from primary search references. EndNote X7.8 was used for reference management [7]. The present systematic review was performed in accordance with the MOOSE (Meta-analysis Of Observational Studies in Epidemiology) Statement [8].

\subsection{Study Selection}

We retained a case report in the systematic review if it reported the description of at least one health outcome in relation to previous $\mathrm{N}_{2} \mathrm{O}$ exposure. The exclusion criteria were as follows: non-English language publication; editorial; narrative review; congress abstract; absence of $\mathrm{N}_{2} \mathrm{O}$ exposure; preventive treatment with vitamin $\mathrm{B} 12$ before $\mathrm{N}_{2} \mathrm{O}$ exposure; and no reported data on at least one of the following biological parameters before vitamin B12 therapy: hemoglobin, hematocrit, mean corpuscular volume (MCV), serum folate, homocysteine, or methylmalonic acid.

\subsection{Data Extraction}

Three investigators (A.O.; J.L.; J.-L.G.) reviewed the titles and abstracts of all citations identified by the literature search. Eligible articles were reviewed by eight investigators (A.O.; M.J.; J.L.; O.H.; C.F.; 
C.S.; E.L.; M.W.; P.F.T.). Disagreement in data extraction was resolved by consensus. The following data were extracted using a predefined extraction form structured in 10 domains: Domain \#1: Case report characteristics (Author, Year, Country); Domain \#2: Patient's demographics (Age, Gender); Domain \#3: Clinical manifestations expressed as binary outcomes (Group 1: Paresthesia of extremities, numbness, or tingling; Quadriparesis or paralysis; Unsteady gait or walking difficulty; Falling, Equilibrium troubles; Weakness; Paraplegia; Hypotonia; Lhermitte sign; Athetoid movement; Ataxia; Seizures; Spasm; Urinary incontinence; Urine retention; Fecal incontinence; Vertigo; Syncope; Polyneuropathy; Bulbar paralysis; Cognitive decline; Impaired memory; Confusion; Disorientation; Lethargy; Neurological deterioration; Group 2: Behavior alteration; Paranoid behavior; Visual hallucination; Agitation; Depression; Suicidal thought; Group 3: Neck pain; Foot pain; Chest pain; Headache; Painful erection; Abdominal pain; Group 4: Constipation, Anorexia, Vomiting; Group 5: Tachypnea; Apnea; Respiratory paralysis; Group 6: Decreased libido; Hyperpigmentation; Domain \#4: Laboratory findings expressed as continuous outcomes [hemoglobin (g/L); hematocrit (\%); MCV (fL); vitamin B12 (pmol/L); folate $(\mu \mathrm{g} / \mathrm{L})$; homocysteine $(\mu \mathrm{mol} / \mathrm{L})$; methylmalonic acid $(\mu \mathrm{mol} / \mathrm{L})]$; We calculated the combined indicator of vitamin B12 status score (cB12) by combining vitamin B12, homocysteine and methylmalonic acid according the Fedosov et al. [9]. The cB12 score defines five vitamin B12 states, as follows: 2 = elevated B12 (cB12 $\geq 1.5), 1=$ adequate B12 status (cB12: -0.5 to 1.5$),-1=$ decreased B12 (cB12: -1.5 to -0.5 ; start B12 supplements), $-2=$ possibly B12 deficient (cB12: -2.5 to -1.5 ; start oral B12), $-3=$ probably B12 deficient (cB12 <2.5; start B12 injections); Domain \#5: Reported diagnoses expressed as binary outcomes (Subacute combined degeneration; Generalized demyelinating polyneuropathy; Myelopathy; Axonal polyneuropathy; Encephalopathy; Recurrent paraparesis; $\mathrm{N}_{2} \mathrm{O}$-related toxicity; Vitamin B12 deficiency; MTHFR deficiency; No specific diagnosis applied); Domain \#7: Setting of $\mathrm{N}_{2} \mathrm{O}$ exposure expressed as binary outcomes (Recreational use; Surgery; Occupational exposure; Pain management; Manipulation under GA; Sleep disturbance; and Munchausen); Domain \#9: $\mathrm{N}_{2} \mathrm{O}$ exposure quantification (frequency: short or regular exposure as defined below; duration of $\mathrm{N}_{2} \mathrm{O}$ exposure in years; $\mathrm{N}_{2} \mathrm{O}$ presentation: cartridge, canister, whippets cream bulbs, anesthesia machine for medical use, or anesthesia machine for personal use); Domain \#10: Magnetic resonance findings expressed as binary outcomes (presence or absence of a T2 signal hyperintensity in the spinal cord).

\subsection{Nitrous Oxide Exposure}

Regular $\mathrm{N}_{2} \mathrm{O}$ exposure was defined as repeated exposure to $\mathrm{N}_{2} \mathrm{O}$, especially in a recreational setting, pain management or occupational exposure, with minimum consumption of one cartridge per month. For each patient, we estimated the average number of cartridges consumed per day and the duration of exposure in years. In the recreational setting, $\mathrm{N}_{2} \mathrm{O}$ was commonly available in the form of small pressurized cartridges which can deliver the equivalent of 8 liters of $\mathrm{N}_{2} \mathrm{O}$ gas at standard temperature and pressure $(8 \mathrm{~g})$ [3]. We quantified the exposure to $\mathrm{N}_{2} \mathrm{O}$ using the following formula: Amount of $\mathrm{N}_{2} \mathrm{O}$ exposure $=$ (average number of cartridges consumed per day $\times$ duration of exposure expressed in years).

\subsection{Main Outcomes and Measures}

The primary outcome of the systematic review was to report on the clinical, laboratory, and magnetic resonance findings of subjects who were exposed to $\mathrm{N}_{2} \mathrm{O}$ in medical and recreational settings. Main clinical findings: Paresthesia in extremities, numbness, tingling; Unsteady gait, walking difficulty; Weakness; Fallings or equilibrium disorders; Lhermitte's sign; and Ataxia. Laboratory findings: Hemoglobin; Hematocrit; MCV; Vitamin B12; Folate; Homocysteine; and Methylmalonic acid. Magnetic resonance finding: Presence of T2 signal hyperintensity in the spinal cord. We assessed two secondary outcomes: (1) to look for predictors of regular $\mathrm{N}_{2} \mathrm{O}$ exposure; (2) to assess the potential association between $\mathrm{N}_{2} \mathrm{O}$ exposure and health outcomes. 


\subsection{Data Synthesis and Analysis}

Categorical variables were summarized as frequency counts and percentages with the $95 \%$ confidence interval $(95 \% \mathrm{CI})$. Quantitative variables were expressed as medians and interquartile range (IQR, $25^{\text {th }}$ and $75^{\text {th }}$ percentiles). We compared proportions using the chi-square test or Fisher's exact test as appropriate. Medians were compared using the Mann-Whitney $U$ test. We assessed correlations using Spearman's rank correlation coefficient. To derive predictors of short $\mathrm{N}_{2} \mathrm{O}$ exposure, we performed univariate logistic regression analysis on binary and continuous variables, using the "Short $\mathrm{N}_{2} \mathrm{O}$ exposure" item as a dependent variable. When a continuous variable was significantly associated with a short $\mathrm{N}_{2} \mathrm{O}$ exposure, we carried out receiver operating characteristic (ROC) analysis for defining its optimal cut-off using the "Short exposure to $\mathrm{N}_{2} \mathrm{O}$ " item as a classification variable [10]. The optimal cut-off was defined using the Youden index J [11]. Receiver operating characteristic analysis outputs included the area under the ROC curve (AUROC), the $95 \% \mathrm{CI}$, and the associated $p$-value using the exact binomial method. In multivariate analysis, all significant items resulting from the univariate logistic regression were integrated into a multivariate logistic regression model using the stepwise method. All variables with $p<0.1$ were included in the model and variables with $P<0.05$ were retained in the model. Results were shown as odds ratios (ORs) and $95 \%$ CI. We assessed model discrimination using ROC analysis and model calibration using the Hosmer and Lemeshow goodness-of-fit test. All statistical analyses were conducted using the SAS ${ }^{\circledR} 9.4$ platform (Cary, NC, USA) and MedCalc for Windows v16.8.4 (Ostend, Belgium) based on a two-sided type I error with an alpha level of 0.05 .

\subsection{Assessment of Bias}

We assessed the potential bias related to population stratification using principal component analysis. We used all the variables related to clinical findings, laboratory findings, reported diagnoses, and $\mathrm{N}_{2} \mathrm{O}$ exposure settings to calculate the ten top eigenvalues. For each patient, the principal components were calculated according to each eigenvalue. We assessed population stratification by visual inspection using two-dimensional and three-dimensional diagrams. The principal component analysis was conducted using SVS 8.8.1 (Golden Helix, Inc. Bozeman, MT, USA).

\section{Results}

\subsection{Literature Review}

The systematic search generated 513 citations of which 132 appeared to be relevant to the systematic review. Of these 132 studies, 47 were not retained by the selection criteria (Table S1), leaving 85 eligible publications (Figure 1 and Table S2). All the case reports included in the systematic review reported individual-level data on 100 patients. Among the 100 reports, most originated from North America $(n=51)$, Western Europe $(n=22)$, China/Taiwan $(n=12)$ and Australia/New Zealand $(n=10)$. 


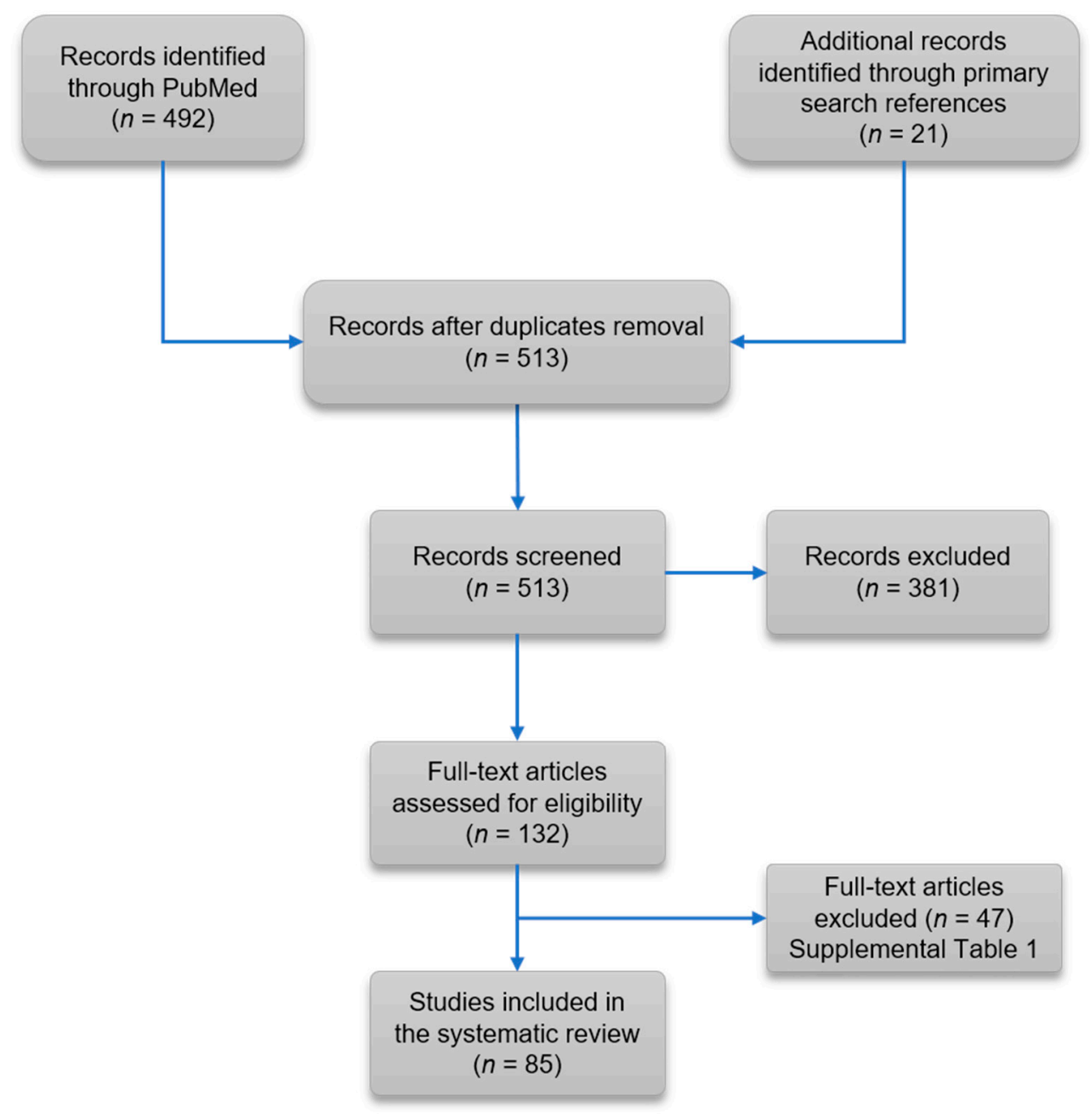

Figure 1. Flow diagram of the systematic review.

3.2. Prevalence of Clinical, Laboratory and Magnetic Resonance Findings in Association with $\mathrm{N}_{2} \mathrm{O}$ Exposure

Among the 100 patients included in the systematic review, the male:female gender distribution was 60:40 and the median age was 27 years (IQR, 22-36; range, 0.4-76.0). Most patients included in the meta-analysis were exposed to $\mathrm{N}_{2} \mathrm{O}$ in the setting of recreational use $(57 \%)$ or surgery $(25 \%)$ (Table 1 ).

Seventy-six percent (76/100) of patients had regular exposure to $\mathrm{N}_{2} \mathrm{O}$. Among them, recreational use (73.7\%, 56/76), occupational exposure $(11.8 \%, 9 / 76)$, and pain management $(7.9 \%, 6 / 76)$ represented the three main $\mathrm{N}_{2} \mathrm{O}$ exposure modes. Among regular users, the median $\mathrm{N}_{2} \mathrm{O}$ exposure was 18.5 cartridge-years, corresponding to a total amount of $54,020 \mathrm{~g}$ of $\mathrm{N}_{2} \mathrm{O}$. The three most frequently reported diagnoses were subacute combined degeneration (28\%), myelopathy $(26 \%)$, and generalized demyelinating polyneuropathy (23\%). A T2 signal hyperintensity in the spinal cord was reported in $68 \%$ of patients who underwent magnetic resonance imaging of the spinal cord (Table 2). 
Table 1. Settings and Quantification of Nitrous Oxide Exposure Among Patients Included in the Individual Patient Data Meta-Analysis.

\begin{tabular}{|c|c|c|c|}
\hline Setting of nitrous oxide exposure & $\mathbf{N}$ & $\mathbf{n}$ & Percentage (95\% CI) \\
\hline Recreational & 100 & 57 & $57.0(47.1-66.9)$ \\
\hline Surgery & 100 & 25 & $25.0(16.4-33.6)$ \\
\hline Occupational exposure & 100 & 9 & $9.0(3.3-14.7)$ \\
\hline Pain management & 100 & 6 & $6.0(1.3-10.7)$ \\
\hline Manipulation under general anesthesia & 100 & 1 & $1.0(0-3.0)$ \\
\hline Munchausen syndrome & 100 & 1 & $1.0(0-3.0)$ \\
\hline Management of sleep disturbance & 100 & 1 & $1.0(0-3.0)$ \\
\hline Frequency of nitrous oxide exposure & $\mathbf{N}$ & $\mathbf{n}$ & Percentage $(95 \% \mathrm{CI})$ \\
\hline Regular & 100 & 76 & $76.0(67.5-84.5)$ \\
\hline Once & 100 & 24 & $24.0(15.5-32.5)$ \\
\hline Quantitative estimates of nitrous oxide exposure* & $\mathbf{n}$ & Median & $\operatorname{IQR}\left(25^{\text {th }}-75^{\text {th }}\right)$ \\
\hline Number of nitrous oxide cartridge per day & 30 & 25 & $8-85$ \\
\hline Duration of nitrous oxide duration (year) & 52 & 0.7 & $0.3-1.5$ \\
\hline Quantification of nitrous oxide exposure (cartridge-years) & 28 & 18.5 & $1.4-99.9$ \\
\hline
\end{tabular}

IQR: interquartile range; N: number of studied patients; n: number of observations. ${ }^{*}$ Among patients with regular nitrous oxide exposure.

Table 2. Magnetic Resonance Findings and Diagnoses Among the Patients Included in the Individual Patient Data Meta-Analysis.

\begin{tabular}{|c|c|c|c|}
\hline Magnetic resonance imaging findings & $\mathbf{N}$ & $\mathbf{n}$ & Percentage $(95 \% \mathrm{CI})$ \\
\hline Presence of T2 signal hyperintensity in the spinal cord & 75 & 51 & $68.0(57.2-78.8)$ \\
\hline Reported diagnoses* & $\mathbf{N}$ & $\mathbf{n}$ & Percentage $(95 \% \mathrm{CI})$ \\
\hline Subacute combined degeneration & 100 & 28 & $28.0(19.0-37.0)$ \\
\hline Myelopathy & 100 & 26 & $26.0(17.3-34.7)$ \\
\hline Generalized demyelinating polyneuropathy & 100 & 23 & $23.0(14.6-31.4)$ \\
\hline Vitamin B12 deficiency & 100 & 14 & $14.0(7.1-20.9)$ \\
\hline Axonal polyneuropathy & 100 & 11 & $11.0(4.8-17.2)$ \\
\hline Encephalopathy & 100 & 2 & $2.0(0-4.8)$ \\
\hline Recurrent paraparesis & 100 & 1 & $1.0(0-3)$ \\
\hline MTHFR deficiency & 100 & 1 & $1.0(0-3)$ \\
\hline Toxicity due to $\mathrm{N}_{2} \mathrm{O}$ with no specific diagnosis applied & 100 & 19 & $19.0(11.2-26.8)$ \\
\hline
\end{tabular}

$\mathrm{N}$ : total number of studied patients; $\mathrm{n}$ : number of observations; $\mathrm{N}_{2} \mathrm{O}$ : nitrous oxide. * Any patient could have more than one diagnosis applied.

At least one neurological symptom was reported in $96 \%$ (92.1-99.9\%) of patients and included the following clinical manifestations by decreasing order of frequency: paresthesia in the extremities $(80 \%)$, unsteady gait or walking difficulties $(58 \%)$, weakness $(43 \%)$, fallings or equilibrium disorders $(24 \%)$, Lhermitte's sign (15\%), and ataxia (12\%) (Table 3 and Figure 2). 
Table 3. Clinical Findings Among the Patients Included in the Individual Patient Data Meta-Analysis.

\begin{tabular}{|c|c|c|c|}
\hline Clinical Findings & $\mathbf{N}$ & $\mathbf{n}$ & Percentage $(95 \% \mathrm{CI})$ \\
\hline Paresthesia in extremities, numbness, tingling & 100 & 80 & $80.0(72.0-88.0)$ \\
\hline Unsteady gait, walking difficulty & 100 & 58 & $58.0(48.2-67.8)$ \\
\hline Weakness & 100 & 43 & $43.0(33.1-52.9)$ \\
\hline Fallings or equilibrium disorders & 100 & 24 & $24.0(15.5-32.5)$ \\
\hline Lhermitte's sign & 100 & 15 & $15.0(7.9-22.1)$ \\
\hline Ataxia & 100 & 12 & $12.0(5.5-18.5)$ \\
\hline Cognitive decline & 100 & 9 & $9.0(3.3-14.7)$ \\
\hline Urinary incontinence & 100 & 8 & $8.0(2.6-13.4)$ \\
\hline Quadriparesis or paralysis & 100 & 7 & $7.0(1.9-12.1)$ \\
\hline Behavior alteration & 100 & 6 & $6.0(1.3-10.7)$ \\
\hline Urine retention & 100 & 5 & $5.0(0.7-9.4)$ \\
\hline Impaired memory & 100 & 5 & $5.0(0.7-9.4)$ \\
\hline Headache & 100 & 4 & $4.0(0.1-7.9)$ \\
\hline Depression & 100 & 4 & $4.0(0.1-7.9)$ \\
\hline Thrombo-occlusive event & 100 & 3 & $3.0(0-6.4)$ \\
\hline Mental confusion & 100 & 3 & $3.0(0-6.4)$ \\
\hline Constipation & 100 & 3 & $3.0(0-6.4)$ \\
\hline Paranoid behavior & 100 & 3 & $3.0(0-6.4)$ \\
\hline Foot pain & 100 & 3 & $3.0(0-6.4)$ \\
\hline Hyperpigmentation & 100 & 3 & $3.0(0-6.4)$ \\
\hline Abdominal pain & 100 & 3 & $3.0(0-6.4)$ \\
\hline Agitation & 100 & 2 & $2.0(0-4.8)$ \\
\hline Fecal incontinence & 100 & 2 & $2.0(0-4.8)$ \\
\hline Lethargy & 100 & 2 & $2.0(0-4.8)$ \\
\hline Seizures & 100 & 2 & $2.0(0-4.8)$ \\
\hline Decreased libido & 100 & 2 & $2.0(0-4.8)$ \\
\hline Visual hallucination & 100 & 2 & $2.0(0-4.8)$ \\
\hline Anorexia & 100 & 1 & $1.0(0-3)$ \\
\hline Apnea & 100 & 1 & $1.0(0-3)$ \\
\hline Athetoid movement & 100 & 1 & $1.0(0-3)$ \\
\hline Bulbar paralysis & 100 & 1 & $1.0(0-3)$ \\
\hline Chest pain & 100 & 1 & $1.0(0-3)$ \\
\hline Disorientation & 100 & 1 & $1.0(0-3)$ \\
\hline Hypotonia & 100 & 1 & $1.0(0-3)$ \\
\hline Neck pain & 100 & 1 & $1.0(0-3)$ \\
\hline Painful erection & 100 & 1 & $1.0(0-3)$ \\
\hline Paraplegia & 100 & 1 & $1.0(0-3)$ \\
\hline Polyneuropathy & 100 & 1 & $1.0(0-3)$ \\
\hline Respiratory paralysis & 100 & 1 & $1.0(0-3)$ \\
\hline Spasm & 100 & 1 & $1.0(0-3)$ \\
\hline Suicidal thought & 100 & 1 & $1.0(0-3)$ \\
\hline Syncope & 100 & 1 & $1.0(0-3)$ \\
\hline Tachypnea & 100 & 1 & $1.0(0-3)$ \\
\hline Vertigo & 100 & 1 & $1.0(0-3)$ \\
\hline Vomiting & 100 & 1 & $1.0(0-3)$ \\
\hline
\end{tabular}

$\mathrm{N}$ : total number of studied patients; $\mathrm{n}$ : number of observations. 


\begin{tabular}{ll}
\hline Clinical, Laboratory, and MR findings & $\%, 95 \% \mathrm{Cl}$ \\
\hline Paraesthesia in extremities, numbness & $80.0(72.0-88.0)$ \\
Unsteady gait, walking difficulty & $58.0(48.2-67.8)$ \\
Weakness & $43.0(33.1-52.9)$ \\
Fallings, equilibrium disorders & $24.0(15.5-32.5)$ \\
Lhermitte's sign & $15.0(7.9-22.1)$ \\
Ataxia & $12.0(5.5-18.5)$ \\
Methylmalonic acid >0.4 $\mu$ mol/L & $93.8(80.4-100)$ \\
Homocysteine $>15 \mu \mathrm{mol} / \mathrm{L}$ & $90.3(79.3-100)$ \\
Vitamin B12 <150 pmol/L & $70.7(60.7-80.8)$ \\
Low haemoglobin status & $55.8(40.3-71.3)$ \\
Low haematocrit status & $52.4(29.1-75.7)$ \\
Mean corpuscular volume $>100 \mathrm{fL}$ & $41.8(28.4-55.3)$ \\
Folate (serum) $<7$ $\mu \mathrm{Lg} / \mathrm{L}$ & $25.0(4.2-45.8)$ \\
Presence of $\mathrm{T2}$ signal hyperintensity &
\end{tabular}

Figure 2. Proportion (95\% confidence interval) of main clinical, laboratory and radiological findings in patients exposed to nitrous oxide $\left(\mathrm{N}_{2} \mathrm{O}\right)$. Low hemoglobin status was defined according to WHO guidelines ( $<13.0 \mathrm{~g} / \mathrm{dL}$ in men; $<12.0 \mathrm{~g} / \mathrm{dL}$ in nonpregnant women) [12]. Low hematocrit status was defined according to WHO guidelines ( $<39 \%$ in men; $<36 \%$ in nonpregnant women) [12].

Patients had a high risk of macrocytic anemia with a median MCV of $100 \mathrm{fL}$ (IQR: 94-103) and median values of hemoglobin of $12.8 \mathrm{~g} / \mathrm{dL}$ (IQR: 10.8-14.2) and $10.7 \mathrm{~g} / \mathrm{dL}$ (IQR: 8.3-12.4) in males and females, respectively. At least one hematological abnormality was retrieved in $71.7 \%$ of cases $(59.9-83.4 \%)$. The proportions of patients with low hemoglobin level $(<13.0 \mathrm{~g} / \mathrm{dL}$ in men; $<12.0 \mathrm{~g} / \mathrm{dL}$ in women, based on WHO guidelines [12]), low hematocrit level ( $<39 \%$ in men; $<36 \%$ in nonpregnant women, based on WHO guidelines [12]), and MCV $>100 \mathrm{fL}$ were $55.8 \%, 52.4 \%$, and $41.8 \%$, respectively (Table 4 and Figure 2). 
Table 4. Laboratory Findings Among the Patients Included in the Individual Patient Data Meta-Analysis.

\begin{tabular}{|c|c|c|c|}
\hline Laboratory findings (continuous) & $\mathbf{n}$ & Median & $\operatorname{IQR}\left(25^{\text {th }}-75^{\text {th }}\right)$ \\
\hline Hemoglobin $(\mathrm{g} / \mathrm{dL})^{*}$ & 43 & 12.0 & $9.1-13.3$ \\
\hline Males & 23 & 12.8 & $10.8-14.2$ \\
\hline Females & 20 & 10.7 & $8.3-12.4$ \\
\hline Hematocrit $(\%) \dagger$ & 21 & 38 & $33-42$ \\
\hline Males & 13 & 40 & $33-44$ \\
\hline Females & 8 & 35 & $32-39$ \\
\hline Mean corpuscular volume (fL) & 55 & 100 & $94-103$ \\
\hline Vitamin B12 (pmol/L) & 82 & 101 & $74-161$ \\
\hline Folate (serum) $(\mu \mathrm{g} / \mathrm{L})$ & 20 & 12.8 & $7.3-14.6$ \\
\hline Homocysteine $(\mu \mathrm{mol} / \mathrm{L})$ & 31 & 55 & 29-111 \\
\hline Methylmalonic acid ( $\mu \mathrm{mol} / \mathrm{L})$ & 16 & 5.0 & $1.1-6.6$ \\
\hline Combined indicator of vitamin B12 status & 33 & -2.802 & $-3.368--1.924$ \\
\hline Laboratory findings (dichotomized) & $\mathbf{N}$ & $\mathbf{n}$ & Percentage $(95 \%, \mathrm{CI})$ \\
\hline Low hemoglobin status* & 43 & 24 & $55.8(40.3-71.3)$ \\
\hline Low hematocrit statust & 21 & 21 & $52.4(29.1-75.7)$ \\
\hline Mean corpuscular volume $>100 \mathrm{fL}$ & 55 & 23 & $41.8(28.4-55.3)$ \\
\hline Vitamin B12 < 150 pmol/L & 82 & 58 & $70.7(60.7-80.8)$ \\
\hline Folate (serum) $<7 \mu \mathrm{g} / \mathrm{L}$ & 20 & 5 & $25.0(4.2-45.8)$ \\
\hline Homocysteine $>15 \mu \mathrm{mol} / \mathrm{L}$ & 31 & 28 & $90.3(79.3-100)$ \\
\hline Methylmalonic acid $>0.4 \mu \mathrm{mol} / \mathrm{L}$ & 16 & 15 & $93.8(80.4-100)$ \\
\hline \multicolumn{4}{|l|}{ Combined indicator of vitamin B12 status $\ddagger$} \\
\hline 2 = elevated B12 (cB12 $\geq 1.5)$ & 33 & 0 & $0.0(-)$ \\
\hline $1=$ adequate $\mathrm{B} 12$ status (cB12: -0.5 to 1.5$)$ & 33 & 3 & $9.1(0-19.4)$ \\
\hline$-1=$ decreased B12 (cB12: -1.5 to -0.5$)$ & 33 & 2 & $6.1(0-14.7)$ \\
\hline$-2=$ possibly B12 deficient (cB12: -2.5 to -1.5$)$ & 33 & 9 & $27.3(11.2-43.3)$ \\
\hline$-3=$ probably $\mathrm{B} 12$ deficient $(\mathrm{cB} 12<-2.5)$ & 33 & 19 & $57.6(39.8-75.4)$ \\
\hline
\end{tabular}

IQR: interquartile range; $\mathrm{N}$ : total number of studied patients; $\mathrm{n}$ : number of observations. ${ }^{*}$ Low hemoglobin status was defined according to WHO guidelines $(<13.0 \mathrm{~g} / \mathrm{dL}$ in men; $<12.0 \mathrm{~g} / \mathrm{dL}$ in nonpregnant women) [12]. + Low hematocrit status was defined according to WHO guidelines ( $<39 \%$ in men; $<36 \%$ in nonpregnant women) [12]. $\ddagger$ The combined indicator of vitamin B12 status (cB12) score was calculated according to Fedosov et al. [9].

Regarding one-carbon metabolism markers, the median plasma vitamin B12 concentration was low (101 pmol/L, IQR: 74-161) with 70.7\% of patients exhibiting a vitamin B12 level $<150 \mathrm{pmol} / \mathrm{L}$, considered as the threshold of vitamin B12 deficiency. The median plasma concentrations of homocysteine and methylmalonic acid were $55 \mu \mathrm{mol} / \mathrm{L}$ (IQR, 29-111) and $5.0 \mu \mathrm{mol} / \mathrm{L}$ (IQR: 1.1-6.6), respectively, with a vast majority of patients exhibiting high homocysteine $(>15 \mu \mathrm{mol} / \mathrm{L})$ and methylmalonic acid ( $>0.4 \mu \mathrm{mol} / \mathrm{L})$ levels $(90.3 \%$ and $93.8 \%$, respectively). According to the cB12 scoring system, $90.9 \%$ of patients exhibited at least a decreased vitamin B12 status and $84.8 \%$ of patients exhibited a possibly or probably deficient vitamin B12 status (Figure 3). The serum folate concentration was in the normal reference range with a median of $12.8 \mu \mathrm{g} / \mathrm{L}$ (IQR, 7.3-14.6) (Table 4). 


\begin{tabular}{lcc}
\hline Combined indicator of vitamin $\mathrm{B} 12$ status & $\%, 95 \% \mathrm{Cl}$ \\
\hline 2 = elevated $\mathrm{B} 12\left(\mathrm{CB}_{12} \geq 1.5\right)$ & $0.0(-)$ \\
$1=$ adequate $\mathrm{B} 12$ status $\left(\mathrm{CB}_{12}:-0.5\right.$ to 1.5$)$ & $9.1(0-19.4)$ \\
$-1=$ decreased $\mathrm{B} 12\left(\mathrm{CB}_{12}:-1.5\right.$ to -0.5$)$ & $6.1(0-14.7)$ \\
$-2=$ possibly B12 deficient $\left(\mathrm{CB}_{12}:-2.5\right.$ to -1.5$)$ & $27.3(11.2-43.3)$ \\
$-3=$ probably $\mathrm{B} 12$ deficient $\left(\mathrm{CB}_{12}<-2.5\right)$ & $57.6(39.8-75.4)$ &
\end{tabular}

Figure 3. Vitamin B12 status according to the combined indicator of vitamin B12 status (cB12) scoring system. The cB12 score was calculated according to Fedosov et al. [9]. Proportion (95\% confidence interval) of main clinical, laboratory and radiological findings in patients exposed to nitrous oxide $\left(\mathrm{N}_{2} \mathrm{O}\right)$. Low hemoglobin status was defined according to WHO guidelines $(<13.0 \mathrm{~g} / \mathrm{dL}$ in men; $<12.0 \mathrm{~g} / \mathrm{dL}$ in nonpregnant women) [12]. Low hematocrit status was defined according to WHO guidelines $(<39 \%$ in men; $<36 \%$ in nonpregnant women) [12].

\subsection{Secondary Outcomes}

\subsubsection{Predictors of Short Nitrous Oxide Exposure}

Univariate Analysis

In univariate logistic regression analysis, among all the variables screened in the systematic review (63 variables: demographics, $\mathrm{n}=2$; clinical findings, $\mathrm{n}=44$; laboratory findings, $\mathrm{n}=7$; magnetic resonance finding, $n=1$; reported diagnoses, $n=9$ ) only three were significantly associated with a short $\mathrm{N}_{2} \mathrm{O}$ exposure, namely: age, vitamin B12 concentration, and MCV (Table 5 and Table S3). In ROC analysis, age, vitamin B12 concentration, and MCV had a significant optimal cut-off in association with a short $\mathrm{N}_{2} \mathrm{O}$ exposure (Table 5). The dichotomized predictors were significantly associated with a short $\mathrm{N}_{2} \mathrm{O}$ exposure in univariate logistic regression: age $\geq 40$ years $(\mathrm{OR}=23.33,95 \%$ CI: 6.84-79.61); vitamin B12 $\leq 74 \mathrm{pmol} / \mathrm{L}(\mathrm{OR}=6.06,95 \% \mathrm{CI}: 2.05-17.90)$, and $\mathrm{MCV}>100 \mathrm{fL}(\mathrm{OR}=9.75$, 95\% CI: 1.93-49.15) (Table 5). 
Table 5. Factors Associated with a Short Exposure to Nitrous Oxide in Univariate and Multivariate Analyses.

\begin{tabular}{|c|c|c|c|c|c|c|c|c|}
\hline Predictor & $\begin{array}{c}\text { Short Exposure to } \\
\mathrm{N}_{2} \mathrm{O} \text {, Median (IQR) }\end{array}$ & $\begin{array}{l}\text { Regular Exposure to } \\
\mathrm{N}_{2} \mathrm{O} \text {, Median (IQR) }\end{array}$ & $\begin{array}{l}\text { AUROCt } \\
\text { Defined } \\
\text { Cut-Off }\end{array}$ & $\begin{array}{c}\text { AUROC, } \\
p \text {-Value }\end{array}$ & $\begin{array}{c}\text { Univariate LR*, } \\
\text { OR }(95 \% \mathrm{CI})\end{array}$ & $\begin{array}{c}\text { Univariate } \mathbf{L R}^{*}, \\
p \text {-Value }\end{array}$ & $\begin{array}{l}\text { Multivariate LR } \ddagger \\
\text { OR }(95 \% \text { CI) }\end{array}$ & $\begin{array}{l}\text { Multivariate } \\
\text { LR } \ddagger p \text {-Value }\end{array}$ \\
\hline $\begin{array}{c}\text { Age } \\
\text { (years) }\end{array}$ & $\begin{array}{c}47 \\
(25-58)\end{array}$ & $\begin{array}{c}26 \\
(22-33)\end{array}$ & $\geq 40$ & 0.0076 & $\begin{array}{c}23.33 \\
(6.84-79.61)\end{array}$ & $<0.0001$ & $\begin{array}{c}23.95 \\
(3.62-158.61)\end{array}$ & 0.001 \\
\hline $\begin{array}{l}\text { Vitamin B12 } \\
(\mathrm{pmol} / \mathrm{L})\end{array}$ & $\begin{array}{c}74 \\
(33-104)\end{array}$ & $\begin{array}{c}110 \\
(81-194)\end{array}$ & $\leq 74$ & 0.0002 & $\begin{array}{c}6.06 \\
(2.05-17.90)\end{array}$ & 0.001 & $\begin{array}{c}10.57 \\
(1.70-65.90)\end{array}$ & 0.01 \\
\hline $\begin{array}{l}\mathrm{MCV} \\
(\mathrm{fL})\end{array}$ & $\begin{array}{c}104 \\
(101-110)\end{array}$ & $\begin{array}{c}97 \\
(92-101)\end{array}$ & $>100$ & $<0.0001$ & $\begin{array}{c}9.75 \\
(1.93-49.15)\end{array}$ & 0.006 & Not retained§ & Not retained§ \\
\hline
\end{tabular}

95\% CI: 95\% confidence interval; AUROC: area under the receiver operating characteristic curve; IQR: interquartile range; LR: logistic regression; MCV: mean corpuscular volume; OR: odds ratio. * Univariate logistic regression analysis on dichotomized variables; † Classification variable: Short nitrous oxide exposure; $\ddagger$ Multivariate logistic regression analysis on dichotomized variables using the stepwise method; § Not retained in the multivariate logistic regression model. 
Multivariate Analysis

Among the variables retained in univariate logistic regression, two remained significant in multivariate logistic regression and were independently associated with a short $\mathrm{N}_{2} \mathrm{O}$ exposure, namely: age $\geq 40$ years $(\mathrm{OR}=23.95,95 \% \mathrm{CI}: 3.62-158.61 ; p=0.001)$ and vitamin $\mathrm{B} 12 \leq 74 \mathrm{pmol} / \mathrm{L}(\mathrm{OR}=10.57$, 95\% CI: 1.70-65.90; $p=0.01$ ) (Table 5). The multivariate regression model was well-calibrated and exhibited a good discrimination (AUROC $=0.908 ; 95 \%$ CI: $0.795-0.970$ ) and overall model fit (Cox and Snell $R^{2}=0.42$; Nagelkerke $\left.R^{2}=0.60 ; p<0.0001\right)$.

\subsubsection{Association Between the Amount of Nitrous Oxide Exposure and Outcomes}

Data regarding the amount of $\mathrm{N}_{2} \mathrm{O}$ exposure was available in 28 patients. In exploratory analyses, the amount of $\mathrm{N}_{2} \mathrm{O}$ exposure was not significantly correlated with any biological variable. Furthermore, the amount of $\mathrm{N}_{2} \mathrm{O}$ exposure was not significantly associated with the most frequently reported diagnoses (subacute combined degeneration, generalized demyelinating polyneuropathy, and myelopathy), the most commonly reported clinical findings (paresthesia in extremities, numbness, tingling; unsteady gait, walking difficulty; weakness; and fallings or equilibrium disorders), or the presence of T2 signal hyperintensity in the spinal cord (Table S4).

\subsubsection{Assessment of Bias}

The visual inspection of 2-D and 3-D plots from the principal component analysis, based on the top five eigenvalues, did not reveal any significant population stratification that could be suggestive of a high risk of bias (Figure S1).

\section{Discussion}

The present meta-analysis highlights the potential side-effects related to $\mathrm{N}_{2} \mathrm{O}$ use with a particularly unfavorable risk-benefit ratio for recreational users who represent more than half of the reported subjects. Among patients with $\mathrm{N}_{2} \mathrm{O}$-related toxicity, neurological or hematological disorders were observed in almost all patients $(96 \%)$. The $\mathrm{N}_{2} \mathrm{O}$-related burden is dominated by vitamin $\mathrm{B} 12$ deficiency and the associated alterations in one-carbon metabolism markers.

Three-quarter of patients with $\mathrm{N}_{2} \mathrm{O}$-related toxicity exhibited a low vitamin B12 status $(<150 \mathrm{pmol} / \mathrm{L})$. Consistently, $85 \%$ of patients exhibited a possibly or probably deficient vitamin B12 status according to the $\mathrm{CB} 12$ scoring system. In the human body, vitamin B12 is physiologically active in two forms: 1) methylcobalamin which represents a cofactor for the methyltransferase enzyme 5-methyltetrahydrofolate-homocysteine methyltransferase, also known as methionine synthase (MTR), and 2) adenosylcobalamin which serves as a cofactor for the enzyme methylmalonyl coenzyme A mutase (MMCoAM) [13-23]. A defect in MMCoAM activity leads to an accumulation of methylmalonic acid while a defect in MTR activity leads to a decrease of methionine and an increase of both homocysteine and S-adenosyl-homocysteine as well as methyltetrahydrofolate concentrations [24]. In the present meta-analysis, vitamin B12 deficiency was evidenced by hyperhomocysteinemia $>15 \mu \mathrm{mol} / \mathrm{L}$ and methylmalonic acid $>0.4 \mu \mathrm{mol} / \mathrm{L}$ in more than $90 \%$ of patients with $\mathrm{N}_{2} \mathrm{O}$-related toxicity. $\mathrm{N}_{2} \mathrm{O}$ exposure is well described as the most effective way to produce vitamin B12 deficiency in animal models [24-27]. $\mathrm{N}_{2} \mathrm{O}$ induces oxidation of the active cobalt center contained in the vitamin B12 chemical structure. It also induces a displacement of the vitamin B12 molecule from MTR with a parallel loss of MTR activity [24].

Several mechanistic hypotheses have been advanced for explaining the association between $\mathrm{N}_{2} \mathrm{O}$ exposure and the occurrence of clinical and biochemical abnormalities associated with vitamin B12 deficiency, notably subacute combined degeneration of the spinal cord in association with hyperhomocysteinemia and elevated levels of methylmalonic acid. Hathout \& El-Saden nicely described these hypotheses in their review paper regarding $\mathrm{N}_{2} \mathrm{O}$-induced myelopathy [24]. Three main mechanistic hypotheses have been put forward as the knowledge in the field progressed: the alteration 
of the MMCoAM pathway [24], the alteration of the methylcobalamin-MTR pathway [24,28,29], and more recently, the imbalance between cytokines and growth factors exhibiting myelinotoxic or myelinotrophic effects [30-34]. Early observations initially suggested that the toxicity of $\mathrm{N}_{2} \mathrm{O}$ occurred primarily through the MMCoAM pathway. However, this was challenged by clinical observations in patients with monogenic inherited disorders associated with methylmalonic acidemia who do not develop subacute combined degeneration [24]. The second hypothesis underlying the relationship between $\mathrm{N}_{2} \mathrm{O}$ exposure and neurological complications is the effect of $\mathrm{N}_{2} \mathrm{O}$ on the methylcobalamin-MTR pathway. Indeed, inherited disorders in MTR activity induce a decrease of methionine and a low methyl-donor status with defective methylation and resulting instability of the myelin sheath. However, this hypothesis was hampered by experiments using the B12-deficient fruit bat animal model. These experiments did not show significant alterations in S-adenosyl-methionine and S-adenosyl-homocysteine in the brain and spinal cord after induction of severe vitamin B12 deficient myelopathy following a combination of dietary deprivation and $\mathrm{N}_{2} \mathrm{O}$ exposure $[24,28,29]$. During the last two decades, much progress has been made in the field of neuroimmunology and have suggested that the pathogenesis of $\mathrm{N}_{2} \mathrm{O}$-induced myelopathy could be explained by an imbalance between cytokines and growth factors exhibiting myelinotoxic (tumor necrosis factor alpha, sCD40:sCD40L dyad, nerve growth factor) or myelinotrophic (interleukin-6 and epidermal growth factor) effects [30-34].

The present meta-analysis reports that patients with regular $\mathrm{N}_{2} \mathrm{O}$ exposure exhibited high methylmalonic acid concentrations. In an experimental rat model, the exposure to $50 \% \mathrm{~N}_{2} \mathrm{O}$ and $50 \%$ $\mathrm{O}_{2}$ mixture during $48 \mathrm{~h}$ was associated with a $70 \%$ reduction of MTR activity in the liver, kidney, and brain with no significant changes in the activity of MMCoAM [35]. Prolonged exposure to $50 \%$ $\mathrm{N}_{2} \mathrm{O}$ induced a further decrease in both MTR and MMCoAM activities (12\% and 32\% of control values after 33 days, respectively). This experiment demonstrates the time-dependent effect that $\mathrm{N}_{2} \mathrm{O}$ exerts on the reduction of enzymatic activity of MTR and MMCoAM. The effect of $\mathrm{N}_{2} \mathrm{O}$ on MTR is evident from the first hours of exposure, while the effect on the MMCoAM requires longer exposure times [35]. Prolonged exposure to $\mathrm{N}_{2} \mathrm{O}$ causes a decrease in the activity of both MTR and MMCoAM with harmful effects on one-carbon metabolism markers [35].

In the present meta-analysis, age $\geq 40$ years, a vitamin B12 concentration $\leq 74 \mathrm{pmol} / \mathrm{L}$, and an $\mathrm{MCV}>100 \mathrm{fL}$ were associated with a short $\mathrm{N}_{2} \mathrm{O}$ exposure, mostly associated with surgery and a more severe clinical picture. These data are in keeping with those of the ENIGMA trial that assessed the effects of $\mathrm{N}_{2} \mathrm{O}$ on patients' outcome after major surgery [36]. In this multicenter randomized trial, 215 patients undergoing $\mathrm{N}_{2} \mathrm{O}$-containing general anesthesia were compared with 179 patients undergoing $\mathrm{N}_{2} \mathrm{O}$-free general anesthesia [36]. The $\mathrm{N}_{2} \mathrm{O}$ group exhibited a significantly increased risk of postoperative hyperhomocysteinemia defined by rising to the $90^{\text {th }}$ percentile of the preoperative homocysteine concentration $(>13.5 \mu \mathrm{mol} / \mathrm{L})(\mathrm{OR}=3.91 ; 95 \%$ CI: $1.82-8.40)$ [36]. Importantly, the occurrence of postoperative hyperhomocysteinemia was significantly associated with an increased risk of complications (risk ratio $(R R)=2.8 ; 95 \%$ CI: 1.4-5.4) and cardiovascular events (RR $=5.1 ; 95 \%$ CI: 3.1-8.5) [36].

The present meta-analysis reports that almost three-quarters of patients regularly exposed to $\mathrm{N}_{2} \mathrm{O}$ were recreational users. The use of $\mathrm{N}_{2} \mathrm{O}$ as a "laughing gas" became popular in the early 1800s during aristocratic laughing gas parties. Over time, the social image of $\mathrm{N}_{2} \mathrm{O}$ as a recreational agent has shifted from a "high-society drug" to a "psychedelic drug", ending up during the last decade as a "hippie crack drug." The 2016/17 Crime Survey for England and Wales reported that 2.6\% of adults aged 16-59 (around 840,000 people) had used $\mathrm{N}_{2} \mathrm{O}$ in the preceding year [37]. Among the youngest subjects, the prevalence of $\mathrm{N}_{2} \mathrm{O}$ use was dramatically higher with $9.3 \%$ of 16-24 year olds reported using $\mathrm{N}_{2} \mathrm{O}$ (males, $11.1 \%$; females, $7.4 \%$ ) in the preceding year [37]. The Global Drug Survey 2014 (GDS2014), conducted in 17 countries out of 74,864 participants, confirmed the increasing popularity of $\mathrm{N}_{2} \mathrm{O}$ as a recreational drug with a lifetime prevalence of $38.6 \%$ and $29.4 \%$ in the UK and US, respectively [38]. Among $\mathrm{N}_{2} \mathrm{O}$ users, the reported rates for persistent numbness and accidental injury were $4.3 \%$ and $1.2 \%$, respectively [38]. The updated results from the GDS2016, with over 
100,000 respondents from over 50 countries, confirmed that $4 \%$ of $\mathrm{N}_{2} \mathrm{O}$ users had symptoms of nerve damage [39]. These data highlight the fact that the recreational use of $\mathrm{N}_{2} \mathrm{O}$ represents a significant public health issue. Awareness campaigns among high-risk populations are eagerly needed, particularly for the 16-24 year olds. Most cases of $\mathrm{N}_{2} \mathrm{O}$-related toxicity were reported in world areas and countries with a low prevalence of B12 deficiency, including North America and Western Europe. Few reports originated from Turkey and Iran, two Middle Eastern countries with an intermediate-to-high prevalence of vitamin B12 deficiency. This highlights the lack of published data that would allow analyzing the risk of $\mathrm{N}_{2} \mathrm{O}$-related outcomes in exposed subjects from countries with a high prevalence of vitamin B12 deficiency, including India, sub-Saharan Africa, and Mexico (Figure S2).

The medical community, particularly physicians who are involved in the emergency departments, anesthesiologists, and surgeons, should be aware of the magnitude of recreational $\mathrm{N}_{2} \mathrm{O}$ exposure in the general population [3]. The evaluation of a patient with a suspicion of $\mathrm{N}_{2} \mathrm{O}$-induced toxicity should include a rigorous clinical evaluation including neurological examination, a laboratory evaluation which consists of a complete blood count, vitamin B12, homocysteine, methylmalonic acid, and folate, and MRI studies where indicated. Patients requiring $\mathrm{N}_{2} \mathrm{O}$-containing anesthesia, particularly those in the setting of elective surgery, should have the same systematic biochemical assessment. In the ENIGMA trial, the vitamin B supplementation before surgery was associated with a significant reduction of the risk for developing post-operative hyperhomocysteinemia (OR $=0.09 ; 95 \%$ CI: 0.03-0.28) [36]. Thus, a strategy based on preoperative screening and the correction of a possible vitamin B12 deficiency, notably in high-risk populations (elderly, vegan, and chronically ill patients) could reduce the risk of $\mathrm{N}_{2} \mathrm{O}$-related disorders.

Two systematic reviews assessed $\mathrm{N}_{2} \mathrm{O}$-related toxicity in recreational use and general anesthesia settings. Garakani et al. reported the main findings related to chronic $\mathrm{N}_{2} \mathrm{O}$ abuse with a focus on neurological sequelae and psychiatric disorders [4]. In this systematic review, no summary effect was calculated regarding medical, laboratory, and radiological findings. Furthermore, biological findings were assessed as categorical variables, and no univariate or multivariate analyses were performed. The authors concluded that chronic $\mathrm{N}_{2} \mathrm{O}$ abuse represents a potentially difficult-to-diagnose condition which could lead to death and that physicians should be aware of $\mathrm{N}_{2} \mathrm{O}$-related toxicity. In the setting of anesthesia, a meta-analysis summarized the evidence from randomized clinical trials associating $\mathrm{N}_{2} \mathrm{O}$ with serious cardiovascular complications [40]. This meta-analysis concluded on the lack of robust evidence for how $\mathrm{N}_{2} \mathrm{O}$ used as part of general anesthesia affects mortality and cardiovascular complications [40].

The present meta-analysis has several strengths. First, we report an individual patient data meta-analysis that collected original data from 100 patients to describe the global burden related to $\mathrm{N}_{2} \mathrm{O}$ toxicity. This approach has also allowed performing univariate and multivariate analyses. Second, the present meta-analysis reported quantitative evidence about the status of one-carbon metabolism markers in the setting of $\mathrm{N}_{2} \mathrm{O}$-related toxicity and highlighted the risk of hyperhomocysteinemia and high methylmalonic acidemia. Third, the meta-analysis of case reports allowed the compilation of unselected patients, thereby reducing the risk of population heterogeneity. The analysis of bias did not reveal a significant stratification of the analyzed population. We acknowledge several limitations. First, we used data extracted from available case reports through a systematic retrospective search. This strategy carries the risk of missing data. Second, laboratory findings were not available for all patients, which resulted in a decrease in the statistical power for univariate and multivariate analyses. Third, in the surgical setting, thromboembolic events potentially associated with $\mathrm{N}_{2} \mathrm{O}$-induced hyperhomocysteinemia could have been mistakenly attributed to the postoperative context, leading to a potential underestimation of the thromboembolic risk associated with $\mathrm{N}_{2} \mathrm{O}$ exposure [36,41-47]. Fourth, in the present systematic review, the exclusion of non-English case reports could have potentially led to selection bias. However, a study that examined the influence of non-English publications on combined estimates of published meta-analyses did not reveal a significant effect after the exclusion of non-English publications [48]. Fifth, because our 
meta-analysis focuses on single patient reports or small case series, we cannot evaluate the frequency of events related to $\mathrm{N}_{2} \mathrm{O}$-induced toxicity. These events may be relatively rare as $\mathrm{N}_{2} \mathrm{O}$ is widely used. Our data point out the need to perform large population studies to better report on $\mathrm{N}_{2} \mathrm{O}$-induced toxicity.

\section{Conclusions}

This meta-analysis points out the association of $\mathrm{N}_{2} \mathrm{O}$ exposure with severe neurological and hematological manifestations and altered one-carbon metabolism markers. These findings lead to raising awareness among the medical community urgently about the risk of $\mathrm{N}_{2} \mathrm{O}$ exposure and particularly in the recreational setting among young people. Population studies are warranted to evaluate whether the correction of vitamin B12 deficiency prevents $\mathrm{N}_{2} \mathrm{O}$-related toxicity in the context of anesthesia and recreational use, particularly in countries with a high prevalence of vitamin B12 deficiency.

Supplementary Materials: The following are available online at http://www.mdpi.com/2077-0383/8/4/551/s1, Table S1: Detail of the Twenty-Nine Studies Excluded from the Systematic Review; Table S2: Detail of the Studies Retained in the Systematic Review; Table S3: Variables Associated with Regular Nitrous Oxide Exposure in Univariate Analyses; Table S4: Association Between the Amount of Nitrous Oxide $\left(\mathrm{N}_{2} \mathrm{O}\right)$ Exposure and Main Clinical, Laboratory, and Magnetic Resonance Findings of the $\mathrm{N}_{2} \mathrm{O}$-Related Disease; Figure S1: Assessment of study bias induced by population stratification using principal component analysis; Figure S2: (a) Worldwide landscape of serum or plasma vitamin B12 concentrations among patients with $\mathrm{N}_{2} \mathrm{O}$-induced toxicity. (b) Worldwide prevalence of subjects with low serum or plasma vitamin B12 concentrations among apparently healthy individuals.

Author Contributions: A.O.: literature review and data extraction; data synthesis and statistical analysis; drafting/revision of the manuscript; analysis and interpretation of data; approved the final draft; M.J.: literature review and data extraction; drafting/revision of the manuscript; approved the final draft; J.L.: literature review and data extraction; drafting/revision of the manuscript; approved the final draft; O.H.: literature review and data extraction; approved the final draft; C.F.: literature review and data extraction; approved the final draft; C.S.: literature review and data extraction; approved the final draft; E.L.: literature review and data extraction; approved the final draft; M.W.: literature review and data extraction; approved the final draft; P.F.T.: literature review and data extraction; approved the final draft; R.G.: drafting/revision of the manuscript; analysis and interpretation of data; approved the final draft; J.-L.G.: study concept; literature review; drafting/revision of the manuscript; analysis and interpretation of data; approved the final draft.

Funding: This research was funded by institutional funding from i-Site Lorraine University of Excellence (ANR-15-IDEX-04-LUE) and by FHU ARRIMAGE and INSERM UMR_S_1256.

Acknowledgments: We thank the administrative and technical staff of INSERM UMR_S_1256.

Conflicts of Interest: The authors declare no conflict of interest.

\section{References}

1. Erving, H.W. The discoverer of anaesthesia: Dr. Horace wells of hartford. Yale J. Biol. Med. 1933, 5, 421-430. [PubMed]

2. Finder, S.G. Lessons from history: Horace wells and the moral features of clinical contexts. Anesth. Prog. $1995,42,1-6$.

3. Randhawa, G.; Bodenham, A. The increasing recreational use of nitrous oxide: History revisited. Br. J. Anaesth. 2016, 116, 321-324. [CrossRef] [PubMed]

4. Garakani, A.; Jaffe, R.J.; Savla, D.; Welch, A.K.; Protin, C.A.; Bryson, E.O.; McDowell, D.M. Neurologic, psychiatric, and other medical manifestations of nitrous oxide abuse: A systematic review of the case literature. Am. J. Addict. 2016, 25, 358-369. [CrossRef] [PubMed]

5. Lassen, H.C.; Henriksen, E.; Neukirch, F.; Kristensen, H.S. Treatment of tetanus; severe bone-marrow depression after prolonged nitrous-oxide anaesthesia. Lancet (Lond. Engl.) 1956, 270, 527-530. [CrossRef]

6. Amess, J.A.; Burman, J.F.; Rees, G.M.; Nancekievill, D.G.; Mollin, D.L. Megaloblastic haemopoiesis in patients receiving nitrous oxide. Lancet (Lond. Engl.) 1978, 2, 339-342. [CrossRef]

7. $\quad$ Reuters, T. Endnote $x 7$; Thomson Reuters: Philadelphia, PA, USA, 2013.

8. Stroup, D.F.; Berlin, J.A.; Morton, S.C.; Olkin, I.; Williamson, G.D.; Rennie, D.; Moher, D.; Becker, B.J.; Sipe, T.A.; Thacker, S.B. Meta-analysis of observational studies in epidemiology: A proposal for reporting. Meta-analysis of observational studies in epidemiology (moose) group. JAMA 2000, 283, 2008-2012. [CrossRef] 
9. Fedosov, S.N.; Brito, A.; Miller, J.W.; Green, R.; Allen, L.H. Combined indicator of vitamin b12 status: Modification for missing biomarkers and folate status and recommendations for revised cut-points. Clin. Chem. Lab. Med. 2015, 53, 1215-1225. [CrossRef]

10. DeLong, E.R.; DeLong, D.M.; Clarke-Pearson, D.L. Comparing the areas under two or more correlated receiver operating characteristic curves: A nonparametric approach. Biometrics 1988, 44, 837-845. [CrossRef]

11. Efron, B.; Tibshirani, R.J. An inTroduction to the Bootstrap; Taylor \& Francis: Abingdon, UK, 1994.

12. Organization of Word Health. Iron Deficiency Anaemia Assessment, Prevention, and Control a Guide for Programme Managers. Available online: http://www.who.int/nutrition/publications/en/ida_assessment_ prevention_control.pdf (accessed on 27 September 2018).

13. Bosco, P.; Gueant-Rodriguez, R.M.; Anello, G.; Barone, C.; Namour, F.; Caraci, F.; Romano, A.; Romano, C.; Gueant, J.L. Methionine synthase (mtr) 2756 (a ->g) polymorphism, double heterozygosity methionine synthase $2756 \mathrm{ag} / \mathrm{methionine} \mathrm{synthase} \mathrm{reductase} \mathrm{(mtrr)} 66 \mathrm{ag}$, and elevated homocysteinemia are three risk factors for having a child with down syndrome. Am. J. Med. Genet. Part A 2003, 121, 219-224. [CrossRef]

14. Brunaud, L.; Alberto, J.M.; Ayav, A.; Gerard, P.; Namour, F.; Antunes, L.; Braun, M.; Bronowicki, J.P.; Bresler, L.; Gueant, J.L. Vitamin b12 is a strong determinant of low methionine synthase activity and DNA hypomethylation in gastrectomized rats. Digestion 2003, 68, 133-140. [CrossRef] [PubMed]

15. Ortiou, S.; Alberto, J.M.; Gueant, J.L.; Merten, M. Homocysteine increases methionine synthase mrna level in caco-2 cells. Cell. Physiol. Biochem. Int. J. Exp. Cell. Physiol. Biochem. Pharmacol. 2004, 14, 407-414.

16. Bosco, P.; Gueant-Rodriguez, R.M.; Anello, G.; Spada, R.; Romano, A.; Fajardo, A.; Caraci, F.; Ferri, R.; Gueant, J.L. Association of homocysteine (but not of mthfr $677 \mathrm{c}>\mathrm{t}, \mathrm{mtr} 2756 \mathrm{a}>\mathrm{g}$, mtrr 66 a $>\mathrm{g}$ and tcn2 $776 \mathrm{c}>\mathrm{g}$ ) with ischaemic cerebrovascular disease in sicily. Thromb. Haemost. 2006, 96, 154-159.

17. Alberto, J.M.; Hamelet, J.; Noll, C.; Blaise, S.; Bronowicki, J.P.; Gueant, J.L.; Delabar, J.M.; Janel, N. Mice deficient in cystathionine beta synthase display altered homocysteine remethylation pathway. Mol. Genet. Metab. 2007, 91, 396-398. [PubMed]

18. Candito, M.; Rivet, R.; Herbeth, B.; Boisson, C.; Rudigoz, R.C.; Luton, D.; Journel, H.; Oury, J.F.; Roux, F.; Saura, R.; et al. Nutritional and genetic determinants of vitamin $\mathrm{b}$ and homocysteine metabolisms in neural tube defects: A multicenter case-control study. Am. J. Med. Genet. Part A 2008, 146, 1128-1133.

19. Fofou-Caillierez, M.B.; Mrabet, N.T.; Chery, C.; Dreumont, N.; Flayac, J.; Pupavac, M.; Paoli, J.; Alberto, J.M.; Coelho, D.; Camadro, J.M.; et al. Interaction between methionine synthase isoforms and mmachc: Characterization in cblg-variant, cblg and cblc inherited causes of megaloblastic anaemia. Hum. Mol. Genet. 2013, 22, 4591-4601. [CrossRef] [PubMed]

20. Ghemrawi, R.; Pooya, S.; Lorentz, S.; Gauchotte, G.; Arnold, C.; Gueant, J.L.; Battaglia-Hsu, S.F. Decreased vitamin b12 availability induces er stress through impaired sirt1-deacetylation of hsf1. Cell Death Dis. 2013, 4, e553. [CrossRef] [PubMed]

21. Bassila, C.; Ghemrawi, R.; Flayac, J.; Froese, D.S.; Baumgartner, M.R.; Gueant, J.L.; Coelho, D. Methionine synthase and methionine synthase reductase interact with mmachc and with mmadhc. Biochim. Et Biophys. Acta 2017, 1863, 103-112. [CrossRef]

22. Green, R.; Allen, L.H.; Bjorke-Monsen, A.L.; Brito, A.; Gueant, J.L.; Miller, J.W.; Molloy, A.M.; Nexo, E.; Stabler, S.; Toh, B.H.; et al. Vitamin b12 deficiency. Nat. Rev. Dis. Primers 2017, 3, 17040. [CrossRef]

23. Green, R. Vitamin b12 deficiency from the perspective of a practicing hematologist. Blood 2017, 129, $2603-2611$. [CrossRef]

24. Hathout, L.; El-Saden, S. Nitrous oxide-induced b(1)(2) deficiency myelopathy: Perspectives on the clinical biochemistry of vitamin b(1)(2). J. Neurol. Sci. 2011, 301, 1-8. [CrossRef]

25. Dinn, J.J.; McCann, S.; Wilson, P.; Reed, B.; Weir, D.; Scott, J. Animal model for subacute combined degeneration. Lancet (Lond. Engl.) 1978, 2, 1154. [CrossRef]

26. van der Westhuyzen, J.; Fernandes-Costa, F.; Metz, J. Cobalamin inactivation by nitrous oxide produces severe neurological impairment in fruit bats: Protection by methionine and aggravation by folates. Life Sci. 1982, 31, 2001-2010. [CrossRef]

27. Metz, J. Cobalamin deficiency and the pathogenesis of nervous system disease. Annu. Rev. Nutr. 1992, 12, 59-79. [CrossRef]

28. Cantrill, R.C.; Oldfield, M.; van der Westhuyzen, J.; McLoughlin, J. Protein profile of the myelin membrane of the fruit bat rousettus aegyptiacus. Comp. Biochem. Physiol. B 1983, 76, 881-884. [CrossRef] 
29. Deacon, R.; Purkiss, P.; Green, R.; Lumb, M.; Perry, J.; Chanarin, I. Vitamin b12 neuropathy is not due to failure to methylate myelin basic protein. J. Neurol. Sci. 1986, 72, 113-117. [CrossRef]

30. Veber, D.; Mutti, E.; Galmozzi, E.; Cedrola, S.; Galbiati, S.; Morabito, A.; Tredici, G.; La Porta, C.A.; Scalabrino, G. Increased levels of the cd40:Cd40 ligand dyad in the cerebrospinal fluid of rats with vitamin b12(cobalamin)-deficient central neuropathy. J. Neuroimmunol. 2006, 176, 24-33. [CrossRef] [PubMed]

31. Scalabrino, G.; Nicolini, G.; Buccellato, F.R.; Peracchi, M.; Tredici, G.; Manfridi, A.; Pravettoni, G. Epidermal growth factor as a local mediator of the neurotrophic action of vitamin b(12) (cobalamin) in the rat central nervous system. FASEB J. 1999, 13, 2083-2090. [CrossRef]

32. Scalabrino, G.; Tredici, G.; Buccellato, F.R.; Manfridi, A. Further evidence for the involvement of epidermal growth factor in the signaling pathway of vitamin b12 (cobalamin) in the rat central nervous system. J. Neuropathol. Exp. Neurol. 2000, 59, 808-814. [PubMed]

33. Scalabrino, G.; Mutti, E.; Veber, D.; Aloe, L.; Corsi, M.M.; Galbiati, S.; Tredici, G. Increased spinal cord ngf levels in rats with cobalamin (vitamin b12) deficiency. Neurosci. Lett. 2006, 396, 153-158. [CrossRef]

34. Scalabrino, G.; Carpo, M.; Bamonti, F.; Pizzinelli, S.; D'Avino, C.; Bresolin, N.; Meucci, G.; Martinelli, V.; Comi, G.C.; Peracchi, M. High tumor necrosis factor-alpha [corrected] levels in cerebrospinal fluid of cobalamin-deficient patients. Ann. Neurol. 2004, 56, 886-890. [CrossRef] [PubMed]

35. Kondo, H.; Osborne, M.L.; Kolhouse, J.F.; Binder, M.J.; Podell, E.R.; Utley, C.S.; Abrams, R.S.; Allen, R.H. Nitrous oxide has multiple deleterious effects on cobalamin metabolism and causes decreases in activities of both mammalian cobalamin-dependent enzymes in rats. J. Clin. Investig. 1981, 67, 1270-1283. [CrossRef] [PubMed]

36. Myles, P.S.; Chan, M.T.; Leslie, K.; Peyton, P.; Paech, M.; Forbes, A. Effect of nitrous oxide on plasma homocysteine and folate in patients undergoing major surgery. Br. J. Anaesth. 2008, 100, 780-786. [CrossRef]

37. Home Office. Drug Misuse: Findings from the 2016/17 Crime Survey for England and Wales. Available online: https://assets.Publishing.Service.Gov.Uk/government/uploads/system/uploads/attachment_ data/file/642738/drug-misuse-2017-hosb1117.Pdf (accessed on 28 July 2018).

38. Kaar, S.J.; Ferris, J.; Waldron, J.; Devaney, M.; Ramsey, J.; Winstock, A.R. Up: The rise of nitrous oxide abuse. An international survey of contemporary nitrous oxide use. J. Psychopharmacol. 2016, 30, 395-401. [CrossRef]

39. Survey, G.D. Key Findings from the Global Drug Survey 2016 (data collected nov 15 January 16). Available online: https://www.Globaldrugsurvey.Com/past-findings/the-global-drug-survey-2016-findings/ (accessed on 28 July 2018).

40. Imberger, G.; Orr, A.; Thorlund, K.; Wetterslev, J.; Myles, P.; Moller, A.M. Does anaesthesia with nitrous oxide affect mortality or cardiovascular morbidity? A systematic review with meta-analysis and trial sequential analysis. Br. J. Anaesth. 2014, 112, 410-426. [CrossRef]

41. Amouzou, E.K.; Chabi, N.W.; Adjalla, C.E.; Rodriguez-Gueant, R.M.; Feillet, F.; Villaume, C.; Sanni, A.; Gueant, J.L. High prevalence of hyperhomocysteinemia related to folate deficiency and the $677 \mathrm{c}->\mathrm{t}$ mutation of the gene encoding methylenetetrahydrofolate reductase in coastal west africa. Am. J. Clin. Nutr. 2004, 79, 619-624. [CrossRef] [PubMed]

42. Bosco, P.; Anello, G.; Ferri, R.; Gueant-Rodriguez, R.M.; Gueant, J.L. Heterogeneity of association between mthfr and stroke among european regions: Additional population studies are needed in italy. Stroke 2006, 37, 761-762. [CrossRef] [PubMed]

43. Gueant-Rodriguez, R.M.; Juilliere, Y.; Nippert, M.; Abdelmouttaleb, I.; Herbeth, B.; Aliot, E.; Danchin, N.; Gueant, J.L. Left ventricular systolic dysfunction is an independent predictor of homocysteine in angiographically documented patients with or without coronary artery lesions. J. Thromb. Haemost. Jth 2007, 5, 1209-1216. [CrossRef]

44. Peyrin-Biroulet, L.; Rodriguez-Gueant, R.M.; Chamaillard, M.; Desreumaux, P.; Xia, B.; Bronowicki, J.P.; Bigard, M.A.; Gueant, J.L. Vascular and cellular stress in inflammatory bowel disease: Revisiting the role of homocysteine. Am. J. Gastroenterol. 2007, 102, 1108-1115. [CrossRef]

45. Spada, R.S.; Stella, G.; Calabrese, S.; Bosco, P.; Anello, G.; Gueant-Rodriguez, R.M.; Romano, A.; Benamghar, L.; Fontaine, T.; Gueant, J.L. Association of vitamin b12, folate and homocysteine with functional and pathological characteristics of the elderly in a mountainous village in sicily. Clin. Chem. Lab. Med. 2007, 45, 136-142. [CrossRef]

46. Gueant-Rodriguez, R.M.; Spada, R.; Moreno-Garcia, M.; Anello, G.; Bosco, P.; Lagrost, L.; Romano, A.; Elia, M.; Gueant, J.L. Homocysteine is a determinant of apoa-i and both are associated with ankle brachial index, in an ambulatory elderly population. Atherosclerosis 2011, 214, 480-485. [CrossRef] [PubMed] 
47. den Heijer, M.; Koster, T.; Blom, H.J.; Bos, G.M.; Briet, E.; Reitsma, P.H.; Vandenbroucke, J.P.; Rosendaal, F.R. Hyperhomocysteinemia as a risk factor for deep-vein thrombosis. N. Engl. J. Med. 1996, 334, 759-762. [CrossRef] [PubMed]

48. Juni, P.; Holenstein, F.; Sterne, J.; Bartlett, C.; Egger, M. Direction and impact of language bias in meta-analyses of controlled trials: Empirical study. Int. J. Epidemiol. 2002, 31, 115-123. [CrossRef] [PubMed]

(C) 2019 by the authors. Licensee MDPI, Basel, Switzerland. This article is an open access article distributed under the terms and conditions of the Creative Commons Attribution (CC BY) license (http://creativecommons.org/licenses/by/4.0/). 